\title{
ANALISIS TINGKAT KEPUASAN MASYARAKAT TERHADAP KUALITAS PELAYANAN PADA KANTOR DINAS KEPENDUDUKAN DAN PENCATATAN SIPIL KABUPATEN BOGOR
}

\author{
${ }^{1)}$ Dasmansyh Adyas, ${ }^{2)}$ Achmad Fahrudin \\ ${ }^{1)}$ Dosen Tetap Program Studi Manajemen, STIE Dewantara \\ J1. Raya Pemda Bojong Depok Baru III Karadenan Cibinong Bogor, Jawa Barat 16913, Indonesia \\ Email: daamansyah.adyas@dewantara.ac.id \\ ${ }^{2)}$ Alumni Program Studi Manajemen, STIE Dewantara \\ J1. Raya Pemda Bojong Depok Baru III Karadenan Cibinong Bogor, Jawa Barat 16913, Indonesia \\ Email: achmad.fahrudin15@gmail.com
}

\begin{abstract}
The purpose of this study was to determine the level of performance / quality of service and the level of community expectations in Disdukcapil Bogor Regency .Data analysis uses the IBb(Importance-Peformance Analysis) method. The results of the study show that: (1) The level of service quality which is the top priority and must be carried out in accordance with the expectations of the community is an indicator that is in quadrants $A$ and $B$ including: provisions, completation of the maintenance process on time. (2) The level of expectation or satisfaction of the community which is considered less important is the indicator that is in quadrant $C$, including: Service personnel having expertise in their fields, service officer in Disdukcapil are responsive to community complaints, service oficers pay attention to the community served and Officers do not ask for fees wild to the community. Whereas quadrant $D$ is an indicator that is considered less important but the community feels satisfied so that it is considered excessive, including: Requirements and service procedures at Disdukcapil do not confuse the public, officers are always at the service and there is AC in the waiting room for services. (3). Overall the expectation or satisfaction of the community towards the service quality performance of the Bogor Regency Disdukcapil still has not 100\%.
\end{abstract}

Keywords: Level of Community Satisfaction, Service Quality.

ABSTRAK

Tujuan penelitian ini adalah untuk mengetahui tingkat kepuasan masyarakat terhadap kualitas pelayanan pada Bidang Pencatatan Sipil di Kantor Dinas Kependudukan dan Pencatatan Sipil Kabupaten Bogorl. Analisis data menggunakan metode IPA (Importance-Peformance Analysis). Hasil Penelitian menunjukkan bahwa: (1) Tingkat kualitas pelayanan yang menjadi prioritas utama dan harus di laksanakan sesuai dengan harapan masyarakat adalah indikator yang berada pada kuadran I dan II diantaranya yaitu: Pelayanan di Disdukcapil mudah dipahami masyarakat, Biaya yang dikeluarkan masyarakat dalam pelayanan sesuai dengan ketentuan. (2) Tingkat harapan atau kepuasan masyarakat yang dinilai kurang penting adalah indicator yang berada pada kuadran III yaitu diantaranya : Petugas pelayanan memiliki keahlian dibidangnya, Petugas pelayanan di Disdukcapil tanggap terhadap keluhan masyarakat, Petugas pelayanan memberikan perhatian terhadap masyarakat yang dilayani dan Petugas tidak meminta pungutan liar terhadap masyarakat. Sedangkan Kuadaran IV adalah indikator yang dianggap kurang penting namun masyarakat mearasa puas sehingga dinilai berlebihan yaitu diantaranya: Persyaratan dan prosedur pelayanan di Disdukcapil tidak membingungkan masyarakat, Petugas selalu ada di tempat pelayanan dan Terdapat AC dalam ruang tunggu pelayanan. (3). Secara keseluruhan timgkat harapan atau kepuasan masyarakat terhadap kinerja kualitas pelayanan Disdukcapil Kabupaten Bogor masih belum 100\% .

Kata kunci: Tingkat Kepuasan Masyarakat, Kualitas Pelayanan. 


\section{PENDAHULUAN}

\subsection{Latar Belakang}

Dinas Kependudukan dan Pencatatan Sipil (Disdukcapil) Kabupaten Bogor merupakan salah satu pelaksana pelayanan administrasi publik di wilayah Jawa Barat. Pelayanan kependudukan ini meliputi pendaftaran penduduk dan pencatatan sipil. Pendaftaran peduduk meliputi pembuatan Kartu Keluarga (KK), Kartu Tanda Penduduk Elektronik (e-KTP), surat pindah, dan Kartu Identitas Anak (KIA), sedangkan pencatatan sipil meliputi pembuatan kutipan akta kelahiran, kutipan akta kematian, kutipan akta perkawinan, kutipan aktaperceraian, pencatatan pengakuan anak dan pengesahan anak, pencatatan perubahan nama, dan pencatatan perubahan kewarganegaraan. Khusus pada bagian Seksi perkawinan ada kebijakan baru dalam sistem informasi administrasi kependudukan (SIAK) versi 7. Sebab, Kementrian Dalam Negeri (Kemendagri) mengeluarkan tampilan baru Kartu Keluarga (KK), di mana warga pun diwajibkan untuk melakukan daftar ulang status perkawinanya ke Dinas Kependudukan dan Pencatatan Sipil (Disdukcapil) untuk memperbaharui informasi dalam berkas kependudukan.Jika sebelumnya Kemendagri mengeluarkan format SIAK versi 6.0, kini pemerintah telah memperharuinya lewat aplikasi SIAK versi 7.0.Bedanya, jika tampilam SIAK versi 6.0 hanya ada $15 \mathrm{kolom}$, namun pada SIAK versi 7.0 ini ditambah lagi dengan kolom golongan darah, status perkawinan, tanggal perkawinan kemudian penambahan kolom kepercayaan, sesuai dengan keputusan MK Nomor: 97/PUU-XIV/2016 tentang Pencantuman Penghayat Kepercayaan dalam Kolom KTP-el dan KK. Adapun data masyarakat Kabupaten Bogor yang sudah terlayani dari jumlah penduduk Kabupaten Bogor yang mencapai
4.699.282 penduduk adalah sebagai berikut

Tabel 1. Jumlah Akta Pencatatan Sipil

\begin{tabular}{|c|c|c|c|c|c|c|c|}
\hline \multirow{2}{*}{ No } & \multirow{2}{*}{ JNIS AKTA } & \multicolumn{6}{|c|}{ TAHCS } \\
\hline & & 2014 & 2015 & 2016 & 2017 & 2018 & 2019 \\
\hline 1 & KELAHIRAN & 62.972 & 70.696 & 90.627 & 138.616 & 207.726 & 156.155 \\
\hline 2 & KEMATLAN & 240 & 309 & 352 & 490 & 1.045 & 1.341 \\
\hline 3 & PERKAWNAN & 410 & 528 & 671 & 782 & 873 & 670 \\
\hline 4 & PERCERAIAN & 65 & 50 & 56 & 65 & 96 & 69 \\
\hline & JUMLAH & 63.687 & 71.583 & 91.706 & 139.953 & 209.740 & 158.235 \\
\hline \multicolumn{7}{|c|}{ JUMLAH TOTAL TERLAYANI } & 734.904 \\
\hline
\end{tabular}

Sumber : Database SIAK sampai bulan September 2019

Kegiatan pelayanan yang diberikan Kantor Dinas Kependudukan dan Pencatatan Sipil akan dinilai dari tingkat kepuasan masyarakat. Penilaian yang diberikan masyarakat menentukan ukuran kinerja pelayanan publik. Kegiatan yang dapat dilakukan untuk mengetahui pelayanan publik adalah dengan mengukur tingkat kepuasan masyarakat. Salah satu metode yang digunakan untuk mengetahui kualitas pelayanan suatu organisasi publik adalah dengan menggunakan Indeks Kepuasan Masyarakat (IKM). Ketentuan Kepuasan masyarakat yang memengaruhi kualitas pelayanan yang diberikan Kantor Disdukcapil menjadi hal menarik untuk dikaji. Berdasarkan pengamatan yang dilakukan oleh penulis ada beberapa hal yang sering dikeluhkan oleh masyarakat terkait pelayanan di kantor Disdukcapil diantaranya:

1. Tingkat keamanan dan kenyamanan masyarakat selama proses pelayananmasih rendah.

2. Asumsi masyarakat terhadap waktu pelayanan di Kantor Dinas Kependudukan dan Pencatatan Sipil yang dinilai masih lambat.

3. Tidak terdapat kotak saran keluhan masyarakat.

4. Kualitas pelayanan berdasarkan tingkat kepuasan masyarakat di Kantor Dinas 
Kependudukan dan Pencatatan Sipil belum diketahui.

5. Kemampuan sumber daya manusia perencana dan pelaksana teknis yang tidak merata.

\subsection{Perumusan Masalah}

Berdasarkan latar belakang yang telah di kemukakan maka penulis merumuskan masalah sebagai berikut:

1. Bagaimana tingkat kinerja /kualitas pelayanan pada Bidang Pencatatan Sipil di Kantor Dinas Kependudukan dan Pencatatan Sipil Kabupaten Bogor?

2. Bagaimana tingkat harapan/kepuasan masyarakat terhadap kualitas pelayanan pada Bidang Pencatatan Sipil di Kantor Dinas Kependudukan dan Pencatatan Sipil Kabupaten Bogor?

3. Bagaimana kesesuaian antara tingkat kinerja pelayanan dengan tingkat harapan masyarakat pada Bidang Pencatatan Sipil di Kantor Dinas Kependudukan dan Pencatatan Sipil Kabupaten Bogor?

\subsection{Tujuan Penelitian}

Berdasarkan rumusan masalah yang telah dikemukakan, maka tujuan dari penelitian ini adalah :

1. Untuk mengetahui tingkat kinerja/kualitas pelayanan pada Bidang Pencatatan Sipil di Kantor Dinas Kependudukan dan Pencatatan Sipil Kabupaten Bogor.

2. Untuk mengetahui tingkat harapan/kepuasan masyarakat terhadap kualitas pelayanan pada Bidang Pencatatan Sipil di Kantor Dinas Kependudukan dan Pencatatan Sipil Kabupaten Bogor.

3. Untuk mengetahui kesesuaian antara tingkat kinerja pelayanan dengan tingkat harapan masyarakat pada Bidang Pencatatan di Kantor Dinas
Kependudukan dan Pencatatan Sipil Kabupaten Bogor.

\section{TINJAUAN PUSTAKA}

\subsection{Landasan Teori}

\subsubsection{Pengertian Pelayanan Publik}

Menurut Keputusan Menteri Pendayagunaan Aparatur NegaraNomor :63/KEP/ M. PAN/7/2004, Pelayanan publik adalah segala kegiatan pelayanan yang dilaksanakan oleh penyelenggara pelayanan publik (instansi pemerintah) sebagai upaya pemenuhan kebutuhan penerima pelayanan publik maupun pelaksanan ketentuan peraturan perundangundangan.Penerima pelayanan publik itu bisa perorangan, masyarakat, instansi pemerintah, dan organisasi berbadan hukum. Pelayanan publik dapat diartikan sebagai pemberian layanan (melayani) keperluan orang atau masyarakat yang mempunyai kepentingan pada organisasi itu sesuai dengan aturan pokok dan tata cara yang telah ditetapkan. Sebagaimana telah dikemukakan terdahulu bahwa pemerintahan pada hakekatnya adalah pelayanan kepada masyarakat. Karenanya Birokrasi publik berkewajiban dan bertanggung jawab untuk memberikan layanan yang baik dan professional (Irsan, 2012: 9).

Dalam keputusan ini diuraikan empat belas unsur yang dijadikan dasar dalam mengukur Indeks Kepuasan Masyarakat (IKM) atas pelayanan yang disajikan pada suatu unit pemerintahan yang meliputi

1. Prosedur pelayanan, yaitu kemudahan tahapan pelayanan yang diberikan kepada masyarakat dilihat dari sisi kesederhanaan alur pelayanan;

2. Persyaratan pelayanan, yaitu persyaratan teknis dan administratif yang diperlukan untuk mendapatkan pelayanan sesuai dengan jenis pelayanannya; 
3. Kejelasan petugas pelayanan, yaitu keberadaan dan kepastian petugas yang memberikan pelayanan (nama, jabatan serta kewenangan dan tanggungjawab);

4. Kedisiplinan petugas pelayanan, yaitu kesungguhan petugas dalam memberikan pelayanan terutama terhadap konsistensi waktu kerja sesuai ketentuan yang berlaku;

5. Tanggung jawab petugas pelayanan, yaitu kejelasan wewenang dan tanggung jawab petugas dalam penyelenggaraan dan penyelesaian pelayanan;

6. Kemampuan petugas pelayanan, yaitu tingkat keahlian dan keterampilan yang dimiliki petugas dalam memberikan/menyelesaikan pelayanan kepada masyarakat;

7. Kecepatan pelayanan, yaitu target waktu pelayanan dapat diselesaikan dalam waktu yang telah ditentukan oleh unit penyelenggara pelayanan;

8. Keadilan mendapatkan pelayanan, yaitu pelaksanaan pelayanan dengan tidak membedakan golongan/status masyarakat yang dilayani;

9. Kesopanan dan keramahan petugas, yaitu sikap dan perilaku petugas dalam memberikan pelayanan kepada masyarakat secara sopan dan ramah serta saling menghargai dan menghormati;

10. Kewajaran biaya pelayanan, yaitu keterjangkauan masyarakat terhadap besarnya biaya yang ditetapkan oleh unit pelayanan;

11. Kepastian biaya pelayanan, yaitu kesesuaian antara biaya yang dibayarkan dengan biaya yang telah ditetapkan;

12. Kepastian jadwal pelayanan, yaitu pelaksanaan waktu pelayanan sesuai dengan ketentuan yang telah ditetapkan

13. Kenyamanan lingkungan, yaitu kondisi sarana dan prasarana pelayanan yang bersih, rapi, dan teratur sehingga dapat memberikan rasa nyaman kepada penerima pelayanan;

14. Keamanan pelayanan, yaitu terjaminnya tingkat keamanan lingkungan unit penyelenggara pelayanan atupun sarana yang digunakan, sehingga masyarakat merasa tenang untuk mendapatkan pelayanan terhadap resiko-resiko yang diakibatkan dari pelaksanaan pelayanan.

\subsubsection{Pengertian Kepuasan Masyarakat}

Kepuasan adalah hasil dari selisih anatara harapan dan kinerja dari fungsi pelayanan. Jika harapan masyarakat terpenuhi atas pelayanan yang diberikan pemberi layanan maka masyarakat akan merasa puas. Akan tetapi jika kinerja layanan berada dibawah harapan maka tentu penerima layanan akan merasa kecewa atau tidak puas. Menurut Parasuraman dkk dalam Tjiptono, Lupiyandi. Terdapat gap anatara pelayanan yang diberikan dengan harapan pelanggan.

\subsection{Kerangka Pemikiran}

Untuk memberikan gambaran menyeluruh tentang rencana penelitian ini , berdasarkan uraian diatasmaka dapat disajikan alur proses penelitian sebagai berikut : 


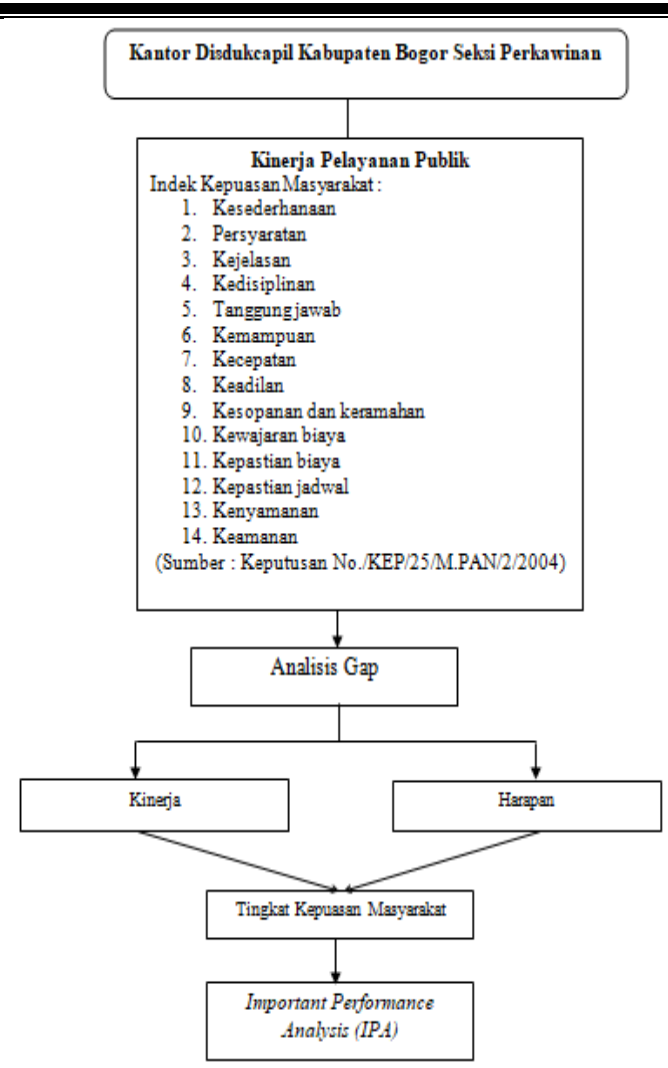

Gambar 1. Kerangka Pemikiran

\section{METODE PENELITIAN}

\subsection{Jenis Penelitian}

Metode penelitian yang di gunakan penulis dalam melakukan kegiatan penelitian ini adalah metode penelitian kuantitatif deskritif. Adanya hubungan dan tingkat variabel ini penting, karena dengan mengetahui tingkat hubungan yang ada, peneliti akan dapat mengembangkannya sesuai dengan tujuan penelitian.

\subsection{Variabel Penelitian}

Variabel dalam penelitian ini adalah tingkat pelayanan dan tingkat kepuasan masyarakat.

\subsection{Lokasi dan Waktu Penelitian}

Penelitian dilakukan pada kantor Dinas Kependudukan dan Pencatatan Sipil Kabupaten Bogor. Waktu penelitian dilakukan kurang lebih 6 bulan di mulai dari bulan Oktober 2019 sampai bulan Maret 2020

\subsection{Populasi dan Sampel}

Populasi dalam penelitian ini adalah semua Masyarakat Kabupaten Bogor yang melakukan pengurasan adminstrasi kependudukan pada bidang pencatatan sipil di Kantor Dinas Kependudukan dan Catatan Sipil kabupaten Bogor. Adapun yang sample yang digunakan berjumlah 140 orang responden dengan menggunakan metode simple random sampling

\subsection{Teknik Pengumpulan Data}

Dalam Penelitian ini, penulis menggunakan teknik pengumpulan data yang digunakan melalui pengumpulan data primer dan data sekunder. Data Primer diperoleh melalui observasi dan utamanya kuisioner.

\subsection{Teknik Analisis Data}

Beberapa metode yang digunakan dalam penelitian ini bertujuan untuk mengukur sejauh mana pengaruh antara kualitas pelayanan publik terhadap kepuasan masyarakat, analisa-analisa tersebut diantaranya :

\subsubsection{Uji Validitas}

Validasi data merupakan suatu ukuran yang menunjukkan suatu tingkat kesahahihan suatu instrumen. Instrumen yang sahih memiliki validasi yangtinggi yang dapat mampu mengukur apa yang diinginkan, mampumengungkapkan data dari variabel yang diteliti secara tepat.

Tinggi rendahnya, validasi instrumen menunjukkan sejauh manadata yangterkumpul tidak menyimpang dari gambaran validasi yang dimaksud. Uji validitas digunakan untuk mengukur sah (valid) atau tidaknya suatu kuesioner. Uji Validitas dihitung dengan membandingkan nilai $r$ hitung (correlated item-total correlation)dengan nilai $\mathrm{r}$ tabel. Jika $\mathrm{r}$ hitung $>\mathrm{r}$ tabel dan nilai positif maka butir 
atau pertanyaan tersebut dinyatakan valid (Ghozali, 2016 :45).

Nilai $r$ tabel diperoleh berdasarkan jumlah sampel yang diambil dengan rumus nilai $\mathrm{df}=\mathrm{n}-2$, pada signifikansi $5 \%$.

\subsubsection{Uji Reliabilitas}

Pengujian realibilitas instrument dilakukan denganinternal konsistensi dengan menggunakan teknik pearson correlation yaitu teknik dengan membandingkan nilai $r$ tabel, maka itemitem tersebut reliabel.

Uji Reliabilitas adalah data untuk mengukur suatu kuesioner yang merupakan indikator dari variabel atau konstruk. Suatu kuesioner dikatakan reliabel atau handal jika jawaban seseorang terhadap pernyataan adalah konsisten atau stabil dari waktu ke waktu. Kehandalan yang menyangkut kekonsistenan jawaban jika diujikan berulang pada sampel yang berbeda. SPSS memberikan fasilitas untuk mengukur reliabilitas dengan uji statistik Cronbach Alpha $(\alpha)$. Suatu konstruk atau variabel dikatakan reliable jika memberikan nilai Cronbach Alpha > 0,60 (Ghozali, 2016).

\subsubsection{Analisa Importance Performance} Anlaysis (IPA)

\subsubsection{Analisis Gap (Tingkat}

\section{Kesesuaian)}

Gap Analysis merupakan suatu metode pengukuran untuk mengetahui kesenjangan (gap) antara kinerja suatu variabel dengan harapan konsumen terhadap variabel tersebut. Gap Analysis itu sendiri merupakan bagian dari metode IPA (Importance-Peformance Analysis). $\mathrm{G}=\mathrm{P}$ (Perceptions)- E (Expectations).

Terdapat dua hal yang dapat terjadi dalam tingkat kesesuaian :

a. Apabila kinerja (persepsi) di bawah harapan maka pelanggan akan kecewa dan tidak puas (Supranto, 2016).

b. Apabila kinerja (persepsi) sesuai dengan harapan maka pelanggan akan puas, sedangkan bila kinerja melebihi harapan maka pelanggan akan sangat puas (Supranto, 2016)

Dalam tingkat kesesuaian $<100 \%$ dapat dijelaskan lagi sebagai berikut(Supranto, 2016) :

1. $0-32 \%$ Sangat Tidak Puas

2. $33-65 \%$ à Tidak Puas

3. $66-99 \%$ Puas

\subsubsection{Model Diagram Kartesius}

Analisa kuadran atau Importance Performance Analysis (IPA) adalah sebuah tehnik analisis deskriptif yang di perkenalkan oleh Martilla dan James tahun 1977. Tehnik ini adalah suatu tehnik analisis yang di gunakan untuk mengindentifikasi faktor-faktor kinerja penting apa yang harus di tunjukan oleh suatu organisasi dalam memenuhikepuasan para pengguna jasa mereka (konsumen).

Awalnya, Martilla dan James memaksudkan metode ini untuk digunakan dalam riset pemasaran dan perilaku konsumen. Hal menarik dari IPA adalah hasil penelitian disampaikan dalam bentuk kuadran 2 dimensi yang bersifat grafis dan mudah diinterpretasi. Hasil kuadran penelitian yang dicontohkan Martilla dan James sebagai berikut:

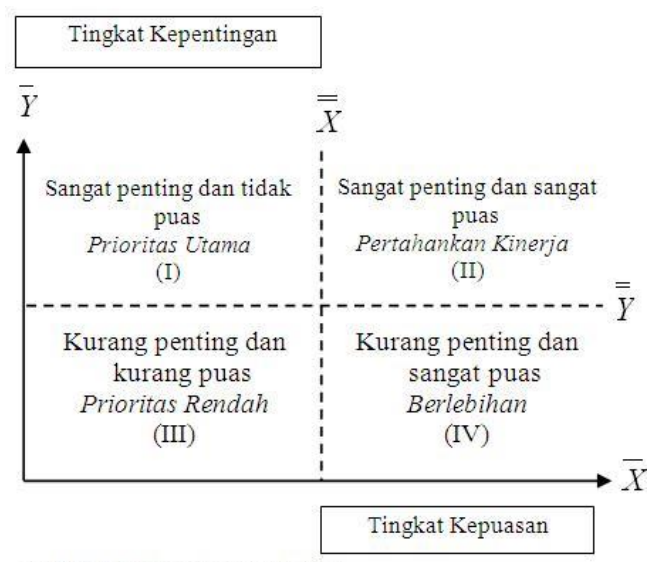

Gambar 2. Diagram Cartesius 
4. HASIL DAN PEMBAHASAN

4.1 Uji Validitas

Pengujian validitas dilakukan berdasarkan analisis item yaitu mengkorelasikan skor setiap item dengan skor variabel (hasil penjumlahan seluruhskor item pertanyaan).Uji Validitas dihitung dengan membandingkan nilai $\mathrm{r}$ hitung (correlated item-total correlation) dengan nilai $r$ tabel. Jika $r$ hitung $>r$ tabel dan nilai positif maka butir atau pertanyaan tersebut dinyatakan valid (Ghozali, 2015 : 45).dalam penelitian ini jumlah sampel 140 dengan signifikansi $5 \%$, dan niali $\mathrm{r}$ tabel sebesar 0,16.

\section{Tabel 2. Hasil Uji Validitas}

\begin{tabular}{|l|c|c|c|c|}
\hline \multirow{2}{*}{ Indikator } & \multicolumn{2}{|c|}{ nilai r hitung } & \multirow{2}{*}{ Nilai r tabel } & \multirow{2}{*}{ Keputusan } \\
\cline { 2 - 3 } & Kinerja & Harapan & & \\
\hline Indikator 1 & 0,628 & 0,721 & 0,165 & Valid \\
\hline Indikator 2 & 0,765 & 0,74 & 0,165 & Valid \\
\hline Indikator 3 & 0,648 & 0,495 & 0,165 & Valid \\
\hline Indikator 4 & 0,803 & 0,849 & 0,165 & Valid \\
\hline Indikator 5 & 0,819 & 0,859 & 0,165 & Valid \\
\hline Indikator 6 & 0,615 & 0,74 & 0,165 & Valid \\
\hline Indikator 7 & 0,57 & 0,495 & 0,165 & Valid \\
\hline Indikator 8 & 0,746 & 0,849 & 0,165 & Valid \\
\hline Indikator 9 & 0,772 & 0,859 & 0,165 & Valid \\
\hline Indikator 10 & 0,779 & 0,255 & 0,165 & Valid \\
\hline Indikator 11 & 0,764 & 0,687 & 0,165 & Valid \\
\hline Indikator 12 & 0,748 & 0,721 & 0,165 & Valid \\
\hline Indikator 13 & 0,803 & 0,74 & 0,165 & Valid \\
\hline Indikator 14 & 0,819 & 0,495 & 0,165 & Valid \\
\hline Indikator 15 & 0,615 & 0,849 & 0,165 & Valid \\
\hline Indikator 16 & 0,57 & 0,859 & 0,165 & Valid \\
\hline Indikator 17 & 0,746 & 0,74 & 0,165 & Valid \\
\hline Indikator 18 & 0,772 & 0,495 & 0,165 & Valid \\
\hline Indikator 19 & 0,779 & 0,849 & 0,165 & Valid \\
\hline Indikator 20 & 0,764 & 0,859 & 0,165 & Valid \\
\hline Indikator 21 & 0,748 & 0,255 & 0,165 & Valid \\
\hline Indikator 22 & 0,803 & 0,687 & 0,165 & Valid \\
\hline Indikator 23 & 0,819 & 0,849 & 0,165 & Valid \\
\hline Indikator 24 & 0,615 & 0,859 & 0,165 & Valid \\
\hline Indikator 25 & 0,57 & 0,255 & 0,165 & Valid \\
\hline Indikator 26 & 0,746 & 0,687 & 0,165 & Valid \\
\hline
\end{tabular}

Sumber : Data primer yang diolah, 2019
Tabel di atas menunjukkan bahwa semua indikator yang digunakan untuk mengukur variabel tingkat kinerja (kualitas pelayanan) dan tingkat harapan (kepentingan) yang digunakan dalam penelitian ini mempunyai koefisien korelasi yang lebih besar dari $r$ tabel yang sebesar 0,165.sehingga dapat disimpulkan bahwa semua pertanyaan dalam indicator dinyatakan valid..

\subsection{Uji Reliabilitas}

Suatu konstruk atau variabel dikatakan reliable jika memberikan nilai Cronbach Alpha $>0,60$.

Tabel 3. Hasil Uji Reliabilitas Variabel Kinerja (X)

Reliability Statistics

\begin{tabular}{|c|c|c|}
\hline $\begin{array}{c}\text { Cronbach's } \\
\text { Alpha }\end{array}$ & $\begin{array}{c}\text { Cronbach's } \\
\text { Alpha Based } \\
\text { on } \\
\text { Standardized } \\
\text { Items }\end{array}$ & N of Items \\
\hline, 967 &, 967 & 28 \\
\hline
\end{tabular}

Sumber : Data primer yang diolah, 2019

Hasil uji reliabilitas tersebut menunjukkan bahwa nilaikoefisien Alpha variabel tingkat kinerja (kualitas pelayanan)yang cukup besar yaitu 0,967 diatas 0,60, Nilai Cronbach Alpha yang ternyata lebih besar dari 0,60, artinya signifikan/reliable. sehingga dapat dikatakan semua konsep pengukur variabel tingkat kinerja (kualitas pelayanan)dari kuesioner adalah reliabel yang berarti bahwa kuesioner yang digunakan dalam penelitian ini. 


\begin{tabular}{l}
\hline \multicolumn{3}{|c|}{ Tabel 4. Hasil Uji Reliabilitas Variabel } \\
Harapan (Y) \\
\begin{tabular}{|c|c|c|}
\hline \multicolumn{3}{|c|}{ Reliability Statistics } \\
$\begin{array}{c}\text { Cronbach's } \\
\text { Alpha }\end{array}$ & $\begin{array}{c}\text { Cronbach's Alpha } \\
\text { Based on } \\
\text { Standardized Items }\end{array}$ & $\begin{array}{c}\text { N of } \\
\text { Items }\end{array}$ \\
\hline, 948 &, 959 & 28 \\
\hline
\end{tabular}
\end{tabular}

Sumber : Data primer yang diolah, 2019

Hasil uji reliabilitas tersebut menunjukkan bahwa nilai koefisien Alpha variabel tingkat harapan (kepuasan masyarakat) yang besar yaitu 0,948 diatas 0,60, Nilai Cronbach Alpha yang ternyata lebih besar dari 0,60, artinya signifikan/reliable. Sehingga dapat dikatakan semua konsep pengukur variabel tingkat harapan (kepuasan masyarakat) dari kuesioner adalah reliabel yang berarti bahwa kuesioner yang digunakan dalam penelitian ini merupakan kuesioner yang handal.

\subsection{Important Performance Analysis} (IPA)

Pada bagian ini dibahas mengenai pemetaan dari nilai kinerja/kualitas pelayanan $(\mathrm{X})$ dan tingkat harapan/kepuasanmasyarakat (Y), dari hasil tersebut maka akan terbentuk matriks yang terdiri dari empat buah kuadran yang masing-masing kuadran menggambarkan skala prioritas dalam mengambil kebijakan baik berupa peningkatan kinerja atau mempertahankan kinerja perusahaan.

Berikut adalah data sebaran kinerja dan harapan masyarakat:

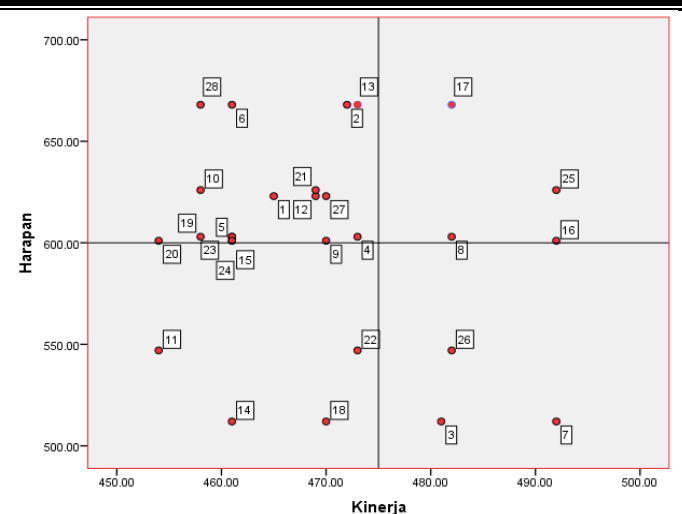

Gambar 3. Hasil Diagram Kartesius Impotance Performance Analysis (IPA)

Sumber : Data primer yang diolah, 2019

Dari gambar tersebut maka dapat diinterpretasikan sebagai berikut:

\section{Kuadran I}

Kuadran A menunjukkan faktor atau atribut yang dianggap sangat penting oleh masyarakat dan masyarakat tidak puas namun tidak terlaksanakan dengan baik oleh perusahaan. Faktor-faktor tersebut adalah:

Indikator 1 : Pelayanan di Disdukcapil mudah dipahami masyarakat

Indikator 2 : Proses pelayanan di Disdukcapil tidak berbelitbelit

Indikator 4: Peraturan dan prosedur pelayanan di Disdukcapil sangat jelas

Indikator 5: Informasi tentang pelayanan di Disdukcapil akurat

Indikator 6: Petugas tanggap dalam menyelesaikan keluhan masyarakat dalam proses pelayanan

Indikator 9: Petugas bertanggungjawab dalam penyelenggaraan pelayanan di Disdukcapil

Indikator 10: Petugas bertanggungjawab dalam menyelesaikan keluhan dan persoalan terkait dengan pelayanan masyarakat 
Indikator 12:Petugas mengetahui dengan jelas rincian serta tata cara pelayanan

Indikator 13 : Petugas terampil dalam memberikan pelayanan kepada masyarakat.

Indikator 15 : Sikap dan perhatian petugas kepada masyarakat baik dan responsif dalam melayani

Indikator 19: Biaya yang dikeluarkan masyarakat dalam pelayanan sesuia dengan ketentuan

Indikator 20: Biaya pelayanan terjangkau oleh masyarakat

Indikator 21 : Masyarakat mengetahui tarif dan biaya pengurusan administrasi di Disdukcapil

Indikator 23 : Penyelesaian proses pengurusan tepat waktu

Indikator 24: Waktu proses pelayanan sesuai dengan ketentuan yang berlaku

Indikator 27 : Masyarakat merasa keamanannya terjamin saat melakukan pengurusan administrasi di Disdukcapil

Indikator 28: Tersedia komputer dan printer yang dapat dimanfaatkan dengan baik oleh petugas pelayanan yang menjamin keamanan data yang berkaitan dengan pelayanan

Dengan demikian indikator-indiktor tersebut menjadi skala prioritas utama perusahaan atau dalam hal ini pihak kantor Disdukcapil Kabupaten Bogor untuk diperbaiki sehingga harapannya masyarakat akan puas dengan pelayanan yang diberikan oleh Disdukcapil.

\section{Kuadran II}

Kuadran B menunjukkan faktor atau atribut yang dianggap sangat penting dan memuaskan masyarakat yang sudah dilaksanakan dengan baik oleh Instansi.

Berdasarkan hasil penelitian indikator yang termasuk dalam kuadran ini adalah:

Indikator 8: Sikap dan perhatian petugas kepada masyarakat baik dan responsif dalam melayani

Indikator 16: Petugas pelayanan tidak bersikap diskriminatif

Indikator 17: Petugas pelayanan bersikap baik dan sopan

Indikator 25: Ventilasi ruangan pelayanan dalam kondisi yang bagus sehingga tidak pengap

Dengan demikian indiakator tersebut perlu dipertahankan kinerjanya oleh pihak perusahaan dalam hal ini adalah kantor DDisdukcapil Kabupaten Bogor.

\section{Kuadran III}

Kuadran III menunjukkan faktor yang dianggap kurang penting oleh masyarakat dan masyarakat menujukkan sikap kurang puas karena tidak terlaksanakan dengan baik.

Berdasarkan hasil penelitian Indikator yang termasuk dalam kuadran ini adalah:

Indikator 11: Petugas pelayanan memiliki keahlian dibidangnya

Indikator 14 : Petugas pelayanan di Disdukcapil tanggap terhadap keluhan masyarakat

Indikator 18 : Petugas pelayanan memberikan perhatian terhadap masyarakat yang dilayani

Indikator 22: Petugas tidak meminta pungutan liar terhadap masyarakat

Dengan demikian indikator-indikator diatas dapat diabaikan/mempunyai skala prioritas pembenahan Disdukcapil Kabupaten Bogor. 


\section{Kuadran IV}

Kuadran IV menunjukkan faktor atau atribut yang dianggap kurang penting oleh masyarakat namun masyarakat merasa sangat puas dan indicator tersebut dilaksanakan dengan berlebihan oleh perusahaan atau instansi.

Berdasarkan hasil penelitian indikator yang termasuk dalam kuadran ini adalah:

Indikator 3: Persyaratan dan prosedur pelayanan di Disdukcapil tidak membingungkan masyarakat

Indikator 7: Petugas selalu ada di tempat pelayanan

Indikator 26: Terdapat AC dalam ruang tunggu pelayanan

Dengan demikian indikator-indiktor tersebut menjadi skala prioritas utama perusahaan atau dalam hal ini pihak kantor Disdukcapil Kabupaten Bogor untuk diperbaiki sehingga harapannya masyarakat akan puas dengan pelayanan yang diberikan oleh Disdukcapil.

\section{KESIMPULAN DAN SARAN \\ 5.1 Kesimpulan}

Berdasarkan uraian di atas maka hasil penelitian ini dapat disimpulkan sebagai berikut :

1. Tingkat kualitas pelayanan yang menjadi prioritas utama dan harus di laksanakan sesuai dengan harapan masyarakat adalah indikator yang berada pada kuadran I dan II yaitu:

a. Faktor yang berada pada kuadran I diantaranya: Pelayanan di Disdukcapil mudah dipahami masyarakat, Informasi tentang pelayanan di Disdukcapil akurat, petugas tanggap dalam menyelesaikan keluhan masyarakat dalam proses pelayanan, sikap dan perhatian petugas kepada masyarakat baik dan responsif dalam melayani, biaya yang dikeluarkan masyarakat dalam pelayanan sesuia dengan ketentuan, penyelesaian proses pengurusan tepat waktu, waktu proses pelayanan sesuai dengan ketentuan yang berlaku, masyarakat merasa keamanannya terjamin saat melakukan pengurusan administrasi di Disdukcapil serta tersedia komputer dan printer yang dapat dimanfaatkan dengan baik oleh petugas pelayanan yang menjamin keamanan data yang berkaitan dengan pelayanan

b. Faktor-faktor yang terdapat pada kuadran II merupakan faktor-faktor yang perlu dipertahankan pelaksanaannya, karena sudah sesuai dengan harapan masyarakat, yaitu sikap dan perhatian petugas kepada masyarakat baik dan responsif dalam melayani, petugas pelayanan tidak bersikap diskriminatif, Petugas pelayanan bersikap baik dan sopan serta yang terakhir adalah ventilasi ruangan pelayanan dalam kondisi yang bagus sehingga tidak pengap.

2. Tingkat harapan atau kepuasan masyarakat yang dinilai kurang penting adalah indikator yang berada pada kuadran III yaitu diantaranya: petugas pelayanan memiliki keahlian dibidangnya, petugas pelayanan di Disdukcapil tanggap terhadap keluhan masyarakat, Petugas pelayanan memberikan perhatian terhadap masyarakat yang dilayani dan petugas tidak meminta pungutan liar terhadap masyarakat. Sedangkan Kuadaran IV adalah indikator yang dianggap kurang penting namun masyarakat merasa puas, sehingga dapat disimpulkan bahwa pelayanan yang diberikan dianggap berlebihan, diantaranya persyaratan yang tidak membingungkan dan ruang yang ber air conditioning.

3. Secara keseluruhan hasil penelitian ini menemukan perbandingan antara harapan masyarkat dengan tingkat pelayanan yang diberikan belum 
memenuhi harapan masyarakat walaupun masyarakat merasa puas atas pelayanan yang telah diberikan oleh Dinas Disdukcapil Kbupaten Bogor.

\subsection{Saran}

Berdasarkan kesimpulan diatas dapat dikemukakan beberapa saran yang kiranya dapat bermanfaat bagi kantor Disdukcapil Kabupaten Bogor yaitu :

1. Memberikan kemudahan masyarakat dalam memperoleh informasi pelayanan yang dibutuhkan misalnya persyaratan dan prosedur pelayanan di Disdukcapil Kabupaten Bogor sehingga tidak membingungkan masyarakat.

2. Hendaknya Kantor Disdukcapil Kabupaten Bogor memberikan jaminan kenyamanan bagi masyarakat yang melakukan pengurusan administrasi misalnya dengan menyediakan ruang tunggu pelayanan yang nyaman dan sejuk.

\section{DAFTAR PUSTAKA}

Akhbar, Husain Usman Purnomo Setiady, 2006. Metodologi Penelitian Sosial, Jakarta : Bumi Aksara.

Anggraini, Lulu Dian Panji Deoranto dan Dhita Morita Ikasari tahun 2014 (Analisis Persepsi Konsumen Menggunakan Metode Importance Performance Analysis Dan Customer Satisfaction Index) Jurnal Industri Vol 4 No 2 Hal 74 - 81 Customer Satisfaction Index

Ghozali, Imam. 2016. Aplikasi Analisis Multivariete Dengan Program IBM SPSS 23 (Edisi 8).Cetakan ke VIII.Semarang : Badan Penerbit Universitas Diponegoro.

Irsan. 2012. "Kualitas Pelayanan Kesehatan

Pada Puskesmas Simpur di Bandar Lampung". Tesis. Universitas Lampung. Bandar Lampung.
Lupiyoadi,Rambat 2006.Manajemen Pemasaran Jasa dan praktek. PT.Salemba Empat: Jakarta.

Moenir, A.S. 2010. Manajemen Pelayanan Umum Di Indonesia.Bumi Aksara : Jakarta. Hlm 88

Ong, Johan Oscar dan Jati Pambudi tahun 2014. (Analisis Kepuasan Pelanggan Dengan Importance Performance Analysis Di SBU Laboratory Cibitung PT Sucofindo (Persero) JATI Undip, Vol IX, No 1, Januari 201

Sekaran, Uma. 2006. Metodologi Penelitian untuk Bisnis.Edisi 4. Salemba Empat, Jakarta.

Sugiyono. 2015. Metode Penelitian Kuantitatif Kualitatif dan R \& D. Bandung: Alfabeta.

Sulistyo Joko, 2012. SPSS 17.Jakarta: Cakrawala

Supranto, J. 2016. Analisis Multivariat: Arti dan Intepretasi. Jakarta. PT Rineka Cipta.

Tjiptono, Fandy.

2014, PemasaranJasa.Prinsip, Penerapan,dan PenelitianAndi Offset, Yogyakarta.

\section{Sumber lain:}

Keputusan Menteri Pendayagunaan Aparatur Negara Nomor 63 Tahun 2004 tentang Pedoman Umum Penyelenggaraan Pelayanan Publik

Keputusan Menteri Pendayagunaan Aparatur Negara Nomor : Kep/25/M.PAN/2/2004 Tentang Pedoman Umum Penyusunan Indeks Kepuasan Masyarakat Unit Pelayanan Instansi Pemerintah.

Undang-Undang Nomor 24 Tahun 2013. Tentang Perubahan Atas UndangUndang Nomor 23 Tahun 2006 Tentang Administrasi Kependudukan Undang-undang No 25 tahun 2009 tentang pelayanan publik. 